Borislav Knežević

University of Zagreb

\title{
(Mis)Learning from American Education: What Is American About Bologna? ${ }^{1}$
}

The paper presents a discussion of some differences and similarities regarding higher education in the United States and Europe (or rather, the changes undertaken in Europe as part of the Bologna process). The focus of discussion is on the issues of degree compatibility, institutional structure, and educational philosophy. Attention is called to the current context of massification and internationalization of higher education, which in turn presents the same kinds of challenges to higher education in both the United States and Europe. However, the paper suggests that, particularly in terms of educational philosophy, the Bologna process has not brought European higher education closer to the American concept of liberal education.

Key words: higher education, the Bologna process, American universities

Among the expectations and anxieties brought about by the Bologna process in European higher education, ${ }^{2}$ those incited by the comparison with the American system of higher education have a special place. However, given the rather broad range of possibilities of constructing comparative analyses of American and European higher education, I will limit this article to three per-

1 This essay is part of research conducted in the project "A Cultural History of Capitalism: Britain, America, Croatia" funded by the Croatian Science Foundation (HRZZ-1543).

2 This article is not based on a comprehensive analysis of Bologna in either the European Higher Education Area (EHEA) or the EU. This would require an empirical overview of great scope. However, the article is intended to point to problematic elements or trends in Bologna, which follow from the combination of the objectives of Bologna and the most general institutional characteristics of European higher education. Many of these characteristics are particularly evident in Croatian higher education. 
spectives that I think are indispensable to the analysis of the problems facing all contemporary "models" of higher education. These are degree compatibility, institutional structure, and educational philosophy.

American higher education, of course, has a diverse range of institutions: private and public institutions, historically black and historically women's colleges, institutions with a historical confessional affiliation, research universities and former land-grant universities (A\&M universities for instance), "national" and "regional" universities, liberal arts colleges, community colleges, schools on semester calendars and schools on quarter calendars, etc. But at the center of American university life still firmly stands the fouryear college, the completion of which is a requirement for graduate programs (masters and doctoral programs) and professional programs (medicine, dentistry, law, business). These are the components that make up American research universities, many of which are private, and many of which are state universities, including a number of highly ranked schools. This structure emerged over the last century, mostly through mutual comparison and emulation, and without much central (i.e., federal) orchestration of the processes of compatibility (in part because delivery of public education is entrusted to the states and not the union). University accreditation processes are also not federal but regional; therefore, American universities assumed their current shape by looking at national examples of what the administrative jargon today calls "best practice." In effect, the high level of compatibility and the dominance of the above model of the research university emerged as a consequence of processes and actions undertaken by the universities themselves, their governing boards and state-level education bodies. In something of a contrast, the harmonization of European higher education launched by the Bologna declaration has been a top-to-bottom process, which began in 1999 as a ministerial platform to be implemented by national higher education systems and individual institutions. The modern American university started to assume its present shape more than a century ago, and its main structural features have remained constant for at least the last half century, whereas the Bologna process was meant to be implemented in a relatively short time- 
span, which understandably gave rise to many concerns over preparedness for it. The prospect of an almost instantaneous transformation produced a great deal of anxiety, reservation, and criticism, some of which was expressed as a fear of the "Americanization" of higher education. On the other hand, the language of the founding texts, the Bologna documents, was in some ways too broad and accommodating of existing situations in European higher education. In particular, the idea that the first cycle could be either three or four years long has effectively opened up room for new incompatibilities within and among national systems with respect to both the first and the second cycle. Recent data shows there is a considerable split in the European Higher Education Area (EHEA) regarding the length of the first cycle, with 58\% of the programs conducted in the 180 ECTS model (effectively three years), and $37 \%$ in the 240 ECTS model (effectively four years). ${ }^{3}$ A particularly difficult problem turned out to be the definition of the baccalaureate (first-cycle degree) as a qualification, as well as the problem of how it does in the labor market. There is also a great deal of variety in delivery of doctoral programs across the EHEA. The third cycle was not in the focus of the early Bologna documents, which were much more concerned with the first two cycles, until the Bergen Communique of 2005 attempted somewhat to redress this lack of focus. Around the world, doctoral programs are now deemed crucial to a "knowledge economy," but it is a matter of much close reading to decipher the steering direction of the Bologna documents on questions of design and the institutional position of doctoral programs within the university, not to mention funding. It is also not entirely clear why the new (Bologna) doctoral programs have been placed within unrealistically set boundaries - the third

3 See The European Higher Education Area in 2015. Bologna Process Implementation Report. http://www.ehea.info/Uploads/SubmitedFiles/5_2015/132824.pdf, p. 52. The quoted data is complicated by the fact that, in a number of countries, programs in so-called regulated professions (medicine, dentistry, architecture, and the like) are often integrated first- and second-cycle programs. As for the second cycle in the EHEA, there is also much variation: for instance, there are four-year programs in the first cycle that are supplemented by two-year programs in the second cycle. In addition, a number of countries feature socalled short-cycle tertiary education programs (usually lasting two years). 
cycle is very often only three years long. ${ }^{4}$

Another development that coincided with the Bologna process ${ }^{5}-$ the establishment of the European Qualifications Framework (EQF) by the European Union - may appear to have the effect of providing an additional stimulation to address the disparate realities of Bologna, as much as to further the cause of comparability of qualifications across Europe. It is through the EQF that a massive effort - a profoundly bureaucratic one - to systematize the "learning outcomes," that is "knowledge," "skills," and "competences," has been launched, leading also to the harmonization of national qualification networks with the EQF. Again, there is no such top-to-bottom process in tertiary education in the US ${ }^{6}$; and consequently, there is no such official bureaucratization of academic standards and practices in curricular issues. We can perhaps hope that this surge of bureaucratism in European higher education is only a stage, perhaps a necessary one to usher in a new kind of academic structure, but it certainly is taxing. Of course, any such categorization of knowledge, competences and skills is bound to raise questions about the validity of its uniform application across the entire range of academic disciplines. Along with this productivist conceptualization of "learning outcomes," there is a tendency in some European countries towards the mechanistic metrification/evaluation of research conducted by academics, a particularly unsuitable practice in some areas of academic work.

4 This is the case in 23 EHEA countries; in the other EHEA countries doctoral programs take three to four years, four years, or more than four years (2015 Bologna Process Implementation Report, p. 65). The Bergen Communique speaks of three to four years as the expected duration of doctoral programs.

5 The Bologna process also includes European countries outside the EU.

6 Interestingly enough, a process of harmonizing standards in elementary secondary education (in mathematics and "English language arts" is currently underway in the United States, known as the Common Core State Standards Initiative, sponsored by the Council of Chief State School Officers and the National Governors Association: http://www. corestandards.org). This has been a state-led effort, and the standards have been adopted in a majority of states, though not all. 
The second perspective, related to the first, is that of institutional structure. Even though there are many voices in American academic debates that bemoan the isolationism of departmental cultures, ${ }^{7}$ the fragmentation of European universities, at least those built on the faculty model, is much more profound. Some degree of disciplinary nationalism is inevitable in academic life; after all, disciplines are a reflection of the necessarily specialized character of specialized knowledge (tautology intended here). But the integration of departments (and "schools" and "colleges") as units of university organization within the common administrative structure and the strategic "mission" of the university is much more pronounced in the United States. There are very few universities in Europe that resemble the institutional structure of the American research university, and possibly none that resemble it in all respects. But more importantly, there is no part of the Bologna process that expressly seeks to establish a comparability of European and American institutional structures.

Governance is an important area of difference in institutional structure. In the US, more often than not, governing boards have a great deal of power in managing the strategic direction of a university (which in the case of public universities is broadly framed by policies defined by either the state legislature or the state department of education); in reality, the prerogative of governance is seldom transformed into projects of sweeping reform (from the working or prospective academic's point of view, the most intrusive form in which that power is manifested is the pressure to cut programs, especially at public universities). In Europe, the Bologna process established a relatively strong platform of reform, and the implementation of the main reform principles into practice is ideally envisaged as a dialogue between the "stakeholders" within and outside the university. There is a great deal of variance among European countries in terms of university governance (of course, there is a

7 A good example of such criticism can be found in David Damrosch's book, We Scholars: Changing the Culture of the University (1995). 
great deal of variety in governance structures and practices between private and state universities in the US, as well). But again, the main distinctive characteristic of the current European situation is the existence of a supranational strategy (the Bologna process), which is in greater or lesser friction or accommodation with national strategies and actual university policies. In Europe, the pressures to reform the university are often perceived as being generated within the political sphere and as encroaching on academic freedom; this is mainly because Bologna was initiated as a political decision at the intergovernmental level and thus conceptualized mostly from above. The most recent period has made clear the necessity of an extensive debate about the relationship between academia and its external "stakeholders," but it has also shown how difficult it is to orchestrate a social conversation about these issues.

There is a common problem converging on both European and American universities with great force at this time: the issue of money. This is not simply a question of funding, nor one of the ideological struggles that have surrounded the various policies on funding public education. The trends of rising tuition at American public universities certainly appear to be similar to the controversies over tuition at public universities in European countries. But here I have in mind primarily the new historical situation of the research university. That is, the funding of research (facilities, equipment, projects, staff) under conditions of massified education and the high costs of developing new knowledge and technologies (big science that requires big budgets) has in recent decades become ever more problematic for a growing number of universities competing to be viewed as research institutions. ${ }^{8}$ If we take as an example a small or even midsize European country, it is questionable whether its universities can develop a full array of research interests (especially in science) that characterize the many top research universities in a

8 For a discussion of the "political economy" of science, see Michael A. Peters, "The Rise of Global Science and the Emerging Political Economy of International Research Collaborations." The primary focus of this article is on science rather than the university, but it proposes an interesting argument about contemporary forms of research collaboration, which have at least in part arisen due to the high costs of big science. 
global power such as the US. This is a challenge even for larger and wealthier European nations and one of the reasons why many research projects in Europe today are international in scope. The EU Framework programs, such as Horizon 2020, which are designed to support the European Research Area and promote intra-European collaboration in research, also have the effect of alleviating some of the funding problems resulting from the new predicament of the research university in Europe - and here the situation of the university is made more complicated by the fact that, in large parts of Europe, fundamental research is often conducted within independent institutes (with which the universities are thus in competition for funding, while also often being in collaboration). Another money-related issue shared by both American and European universities is the problem of what to do with commercially viable products or processes developed by researchers working within the institutional structure of the university - the problem of patents, rights, sales, academic spin-offs and incubators, etc. Public universities face these kinds of problems as much as private ones, and it is not easy to establish regulatory standards in this field that would protect the educational aspects of university activities, ensure that academic freedom is not compromised by commercialization of research, and prevent conflicts of interest.

The third perspective I wish to highlight has to do with curriculum, and in a wider sense, the philosophy of education underlying curricular design. In this regard, it is probably not a stretch to claim that the Bologna process has not pushed European education significantly closer towards the American model. In the broadest of terms, the American model is still underwritten by the concept of liberal education, which means that undergraduate students are required to take courses in the broadest range of fields and disciplines alongside courses in their major (which is usually less than half their total course load). In contrast, students at European universities tend to take 
courses mostly in their major (or two majors). ${ }^{9}$ The difference is much more than mere arithmetic: these arrangements have far-reaching consequences for the idea of university education, university structure, and students' choice of majors. Undergraduate degree requirements in the United States are such that there is less emphasis on vocation and specialization than at European universities; for students studying at American universities, this means more choice in terms of the courses they can take. This in turn also means that American universities have to maintain a wide range of disciplines and courses on offer, while at the same time they may evoke student preferences regarding courses and majors in making decisions about developing, restructuring, or cutting programs. Here, the size of the American educational system also plays a role, in the sense that the sheer number of universities and programs they offer may offset large program shifts at individual institutions from a big picture point of view. A similar effect proceeds from the categorization of higher education institutions; even though there is no official nation-wide (federal) classification, there are clear ways in which HEIs get recognized as belonging to different categories. For instance, the so-called Carnegie classification differentiates between (private and public) doctoral universities, master's colleges and universities, and baccalaureate colleges; on the other hand, since the 1960s, some states, like California, have developed three differently tuned state-wide public systems (the University of California system, the California State University system, and the California Community College system); other states have structured their public higher education systems in

9 There is, of course, a great deal of variety in Europe in this regard; for instance, Heidelberg University offers different levels of focus in undergraduate programs $(100 \%, 75 \%$, $50 \%, 25 \%)$, and not all levels of focus are available in all subjects. See http://www.uni-heidelberg.de/courses/prospective/academicprograms/index.html. On the other hand, the University of Manchester offers an undergraduate three-year English program ("course" in English usage), as well as a four-year undergraduate program in English literature and French (or German, etc.). See http://www.manchester.ac.uk/study/undergraduate/courses/2016/00060/english-literature-3-years-ba/. Such variations could compose a long list, but the point is that the general structure of the undergraduate curriculum is unlike that of the American undergraduate curriculum. 
comparable ways. In reality, the stratification of universities can be observed in the fact that some universities (the ones that are generally better funded, for one reason or another) tend to place a great deal of emphasis on research, and that they also tend to develop a wide range of strengths in research and teaching (while often also focusing on particular areas where they see themselves as especially innovative or competitive). On the other hand, a number of schools which have to make do with less funding expect their academic staff to focus more on teaching than research and offer a more narrow range of disciplines and majors, while their graduates receive diplomas which carry more symbolic capital regionally than nationally, and certainly less symbolic capital than diplomas issued by top research institutions, public or private. However, from the point of view of students, the symbolic capital of a university degree has undergone some change in recent years regarding employment opportunities, and not for the better. In the US, the undergraduate degree was a rather effective credential in the labor market in the second half of the twentieth century. It was generally pursued with the understanding that employment would not be hard to find. The recent crisis, which has reduced employment opportunities (at a time when the overall number of university graduates is still growing ${ }^{10}$ ), has motivated higher enrolment particularly in post-baccalaureate programs. In Europe, undergraduates tend to receive a more specialized education, and universities tend to develop and phase out programs and determine enrolment quotas based on the assessment of social demand (which is done by the universities themselves or funding bodies such as education ministries or agencies), rather than on student preferences (it is a widespread practice in Europe to enroll students in major programs, which means that universities have to plan enrolment quotas; in contrast, students at American universities are not usually required to declare their major until the end of the second year). It would be highly interesting to investigate com-

10 "In fall 2015, some 20.2 million students are expected to attend American colleges and universities, constituting an increase of about 4.9 million since fall 2000" (http://nces. ed.gov/fastfacts/display.asp?id=372). 
prehensively and comparatively, within the EHEA and in the period since the launching of Bologna, the different policies undertaken by European universities, policy makers, legislators, and other "stakeholders" to address issues of educational philosophy, program design and central planning of the educational system. Back to the question of the size of the educational system: in the US the universities fall into an unofficial but recognizable educational/ research niche (the positioning is often planned and managed on the state level, and at the same time influenced by nation-wide trends), but this could not work in smaller European countries, in which it is necessary to develop more compact and focused strategies of national higher education (in terms of founding, developing, categorizing, and funding higher education institutions). Conceptualizing the place and framework of national higher education within European and global contexts has indeed turned out to be the central challenge of the new predicament of the European university. Much of the harmonizing effort of Bologna has focused on the harmonization and recognition of qualifications, which in turn has promoted greater mobility of students and degree holders. American university students and graduates are very mobile nation-wide; this is only beginning to change across Europe (even though some more prestigious European research universities have been traditionally able to attract considerable numbers of international students). In addition, the employability of university graduates is bound to become an increasingly European affair, which may sometimes result in brain drain from some areas of Europe, the ineluctable consequence of the fact of uneven economic development within the EU.

University life in the United States is an experience that is unified spatially (the concept of the campus facilitates the idea of a common curriculum, so to speak), academically (as the freedom to study in different fields of knowledge, to cite one of Humboldt's academic freedoms), and culturally (as an institution sustaining a lively debate about its commonalities and goals across disciplinary divides); this kind of concentration and integration is less present in European contexts, where very different, centrifugal features obtain, reflecting different historical trajectories in the development of uni- 
versities. European universities are often spatially scattered in their city environment, students often have limited choice in pursuing different subjects of study within the framework of the university (due to spatial but also program limitations), and one of the common problems of European universities has been facilitating dialogue on integration. In spite of the drive for inter-European harmonization and the tangible reforms that have often caused vocal opposition, generally speaking, with regard to educational philosophy, Bologna has not made European higher education significantly more similar to the American model.

However, what Bologna does make obvious (though not always in a clearly effective way) is that universities in Europe are now facing the same kinds of challenges as the universities around the world. The current administrative focus at universities worldwide, with catchphrases such as excellence and innovation, is also often expressive of a new prominence of the issue of funding, and debates on the funding of higher education seem to dominate the academic conversation these days. Yet the Bologna moment is irreducible to simply financial or economic issues. We should remember here two important elements of the global context of the Bologna moment. The first is the lingering global dominance of the American university, which has attracted both researchers and students from around the world during the last half-century much more than any other place. In this sense, Bologna clearly started as an expression of the European intention to compete globally in a more organized way than it had been able to do in the past. (French and German universities, but especially those in the UK, are very successful in attracting foreign students already. $)^{11}$ Europe is not the only area trying to increase the global competitiveness of its higher education. High levels of investment in education and research are no longer limited to rich Western countries; in some Asian countries investment in research is quickly catching up to West-

11 See, for instance, UNESCO's data on student mobility at http://www.uis.unesco.org/ Education/Pages/ international-student-flow-viz.aspx. 
ern standards. For instance, China was the world's second in spending on R\&D in 2009, with South Korea posting high numbers as well (Hazelkorn 14). Some analyses suggest that the countries of Mercosur are in the early stages of harmonizing their higher education, possibly under the influence of the Bologna process. ${ }^{12}$ Global ranking of higher education institutions has now become a matter of global media play, with ARWU, a Chinese-based ranking started in 2003, now enjoying a great deal of citation.

The second element of the Bologna context has to do with an important threshold in the history of higher education: on the national stage, higher education has become a matter of mass education ${ }^{13}$ in a number of countries, a situation decisively different from that of only half a century ago, when university education was still considered by and large the preserve of social elites (no longer possible after the 1960s). In the US the decisive turn to massification happened in the 1960s, and the numbers of tertiary education students are still rising. ${ }^{14}$ Most European countries have been steadily working to raise the percentages of university graduates for several decades now, encouraged by various EU objectives. In Croatia, there was a sharp rise in tertiary enrollment at the turn of the century, and it is estimated that in the 30-34 age group the percent of those with completed tertiary education in 2014 was $32.2 \%$ (the EU average was $37.9 \%$ ), and in addition there is a high dropout rate, ${ }^{15}$ altogether meaning that large numbers of secondary-school

12 See Mario Luiz Neves de Azevedo, "The Bologna Process and Higher Education in Mercosur: regionalization or Europeanization?”

13 The massification of higher education should not be conflated with the issue of equal access to higher education. It is likely that the beneficiaries of massification have often come from the more affluent circles in many different national contexts, but it is also common sense to propose that massification necessarily affects the social dimension of education. 14 The percentage of recent high-school completers enrolling in college rose from $45.1 \%$ in 1960 (already a relatively high percentage) to $68.4 \%$ in 2014. See http://nces.ed.gov/ programs/digest/d15/tables/dt15_302.10.asp.

15 See Pregled obrazovanja i osposobljavanja za 2015. Hrvatska, p. 7. http://public.mzos. hr/ Default.aspx?sec=2194. 
completers pursue tertiary education. In other words, in Croatia, higher education has recently been showing features of massification. How to manage this massification from the point of view of academia as well as the society at large is a momentous issue, and Bologna in all its local variants can be seen as both a symptom and an example of the process.

The imperatives of mass higher education and internationalization (which in turn calls for dealing with the issue of degree compatibility) are common predicaments for both American and European higher education. The consequences are comparable in spite of the differences: since the numbers of undergraduate degrees in specific age groups are becoming quite high, in the US many are seeking an advantage in the labor market by pursuing post-baccalaureate degrees (especially in the last 15 years, the period coinciding with pronounced economic instability). Although the reasons are not quite the same, a similar trend can be observed in Croatia, where master's degrees are routinely pursued at the expense of first-cycle degrees. ${ }^{16}$ In addition, due to processes of internationalization and brain drain, it is becoming increasingly awkward to "plan" higher education and research strategies simply in terms of the national context. The massification of tertiary education is an equally important issue facing universities around the world, and in this context one often hears talk of the need to streamline university education into a rationalized outfit focused on production of "experts" and "specialists." Observers of tertiary education in many European countries can hardly ignore the fact that a narrow approach (especially a narrowly profession-based approach) to curricular design of the first and second cycles often in practice means endorsing this kind of utilitarian understanding of the university, a dubious proposition for a variety of reasons, one of which being that, at this his-

16 In fact, almost $75 \%$ of first-cycle degree holders enroll in the second cycle. See Pregled, p. 7. On the other hand, in the recent period the unemployment rates for secondary-school completers and tertiary education completers in the 25-29 age group have been roughly the same, a little more than $20 \%$ (Pregled, Slika 3, p.8), which suggests that a tertiary qualification in the recent context of the Croatian economy is not an advantage over secondary-school qualification in finding employment. 
torical juncture, the character of knowledge is changing so fast that breadth rather than narrowness in education seems the more reasonable way forward, not to speak of the various other advantages of a liberal university curriculum as opposed to an exclusive educational focus on expertise. In this regard, the Bologna process has so far remained largely unconcerned with the dangers of educational utilitarianism, falling short of learning productively from the American model of liberal education.

\section{Works Cited}

Ash, Mitchell G. "Bachelor of What, Master of Whom? The Humboldt Myth and Historical Transformations of Higher Education in German-Speaking Europe and the US.” European Journal of Education 41.2 (2006): 245-67. Print.

de Azevedo, Mario Luiz Neves. “The Bologna Process and higher education in Mercosur: regionalization or Europeanization?” International Journal of Lifelong Education, 33.3 (2014): 411-27. Print.

BA English Literature. University of Manchester. Web. 15 March 2016. <http://www.

manchester.ac.uk/study/undergraduate/courses/2016/00060/english-literature-3years-ba/>

Common Core. State Standards Initiative. Web. 15 March 2016.

$<\mathrm{http}: / /$ www.corestandards.org >

Damrosch, David. We Scholars. Changing the Culture of the University. Cambridge:

Harvard University Press, 1995. Print.

Digest of Education Statistics. National Center for Education Statistics. Web. 15 March 2016. <http://nces.ed.gov/programs/digest/d15/tables/dt15_302.10.asp>

The European Higher Education Area in 2015. Bologna Process Implementation Report. Web. 15 March 2016. <http://www.ehea.info/ Uploads/SubmitedFiles/ 5_2015/132824.pdf>

Fast Facts. National Center for Education Statistics. Web. 15 March 2016. <http://nces. ed.gov/fastfacts/display.asp?id=372>

Hazelkorn, Ellen. "Reflections on a Decade of Global Rankings: what we've learned and outstanding issues." European Journal of Education 49.1 (2014): 12-28. Print. 
Peters, Michael A. “The Rise of Global Science and the Emerging Political Economy of International Research Collaborations." European Journal of Education 41.2 (2006): 225-44. Print.

Pregled obrazovanja i osposobljavanja za 2015. Hrvatska. Web. 15 March 2016. $<$ http://public.mzos.hr/Default.aspx?sec=2194>

UNESCO Institute for Statistics. Web. 15 March 2016. <http://www.uis.unesco.org/ Education/Pages/international-student-flow-viz.aspx >

University of Heidelberg. Web. 15 March 2016. <http://www.uni-heidelberg.de/courses/ prospective/academicprograms/index.html > 